\title{
The Access to Medicines: The Weak Link of the Exemption of Healthcare Payment Policy for the Elderly in Senegal
}

\author{
Ka Ousseynou ${ }^{1,2}$, Sow Papa Gallo ${ }^{1, *}$, Bop Martial Coly ${ }^{1}$, Mbaye El Hadji ${ }^{3}$, Tall Alioune Badara ${ }^{1}$, \\ Touré Moustapha ${ }^{2}$
}

${ }^{1}$ Faculty of Health and Sustainable Development, Alioune Diop University, Bambey, Senegal

${ }^{2}$ Centre of Gerontology Center of Ouakam, Dakar, Senegal

${ }^{3}$ Simone de Beauvoir Institute of Concordia University, Montréal, Canada

Email address:

papagallo.sow@uadb.edu.sn (S. P. Gallo)

${ }^{*}$ Corresponding author

\section{To cite this article:}

Ka Ousseynou, Sow Papa Gallo, Bop Martial Coly, Mbaye El Hadji, Tall Alioune Badara, Touré Moustapha. The Access to Medicines: The Weak Link of the Exemption of Healthcare Payment Policy for the Elderly in Senegal. Science Journal of Public Health.

Vol. 5, No. 4, 2017, pp. 307-312. doi: 10.11648/j.sjph.20170504.15

Received: April 5, 2017; Accepted: April 21, 2017; Published: June 15, 2017

\begin{abstract}
The institutionalization of the Plan Sesame in Senegal or free access to healthcare for the elderly translates a real political will of decision-makers to answer the sanitary concerns of this category of vulnerable population. The objective of this study is to estimate the effectiveness of the free access to the Plan Sesame and to collect the appreciations of the recipients of the Plan. This study is based on a data connection of qualitative data in 2010 with the elderly and decision-makers and on a transverse quantitative and qualitative study in 2011 made to the only geriatric hospital of the country. The elderly are particularly affected by chronic pathologies and most drugs of which they need are not dealt by the Plan. They must buy them in private pharmacies. The not provision of these drugs known as of speciality favors the recourse to the illicit market of drugs with traditional medicine and even with the therapeutic abandonment. Moreover it worsened the social inequalities of health within the recipients of this Plan.
\end{abstract}

Keywords: Health Policy, Free Access to Healthcare, Drugs, Elderly, Senegal

\section{Introduction}

According to the demographic data, there are approximately 700.000 elderly in Senegal of more than 60 years with 5 geriatricians among whom 4 work In Dakar. Nevertheless $63 \%$ of this category of population lives in rural areas [1]. It is necessary to underline that $70 \%$ of the elderly have no social security cover. This social security cover is insured by the family which is currently confronted with economic difficulties (unemployment of young people, poverty). As regards the poverty, the investigations reveal that the incidence of poverty increases with the age of the head of household [1]. Indeed $63 \%$ of the household managed by an elderly of 55 years and more live below the poverty line. Moreover $38 \%$ of the households of more than 10 children are managed by an elderly [1]. They are sometimes obliged to continue their activities to provide for the needs of their family. On the health care management the elderly are generally people with multiple illnesses and they are exposed as their counterparts of the countries of the North to the chronic diseases that require a long term care [2]. Unfortunately these diseases burden heavily the thin budget of the family or the retirement pension. Also the elderly experience financial difficulties to deal with their health problems. And according to investigation [1] the purchase of medicine represents $80 \%$ of the cost of an episode of disease at the elderly in Senegal. This reality is also attested in other African countries as in Burkina Faso [4]. The introduction of the Plan Sesame or policy of free medical care for the elderly people [5] constituted a real will of the political decision makers to answer the medical concerns of this category of population $[6,7]$ contrary to the majority of the African 
countries [6]. So all the medical services connected to the coverage of the elderly (consultations, ancillary medical balance, hospitalization and medicines) should be supported by the Plan Sesame. The objective of this study is to estimate the effectiveness of services offered by the Plan Sesame and to collect the appreciations of the beneficiaries towards this Plan.

\section{Methodologie}

The study is based on two inquiries. The first one [7] consisted of a collection of qualitative data between 2010 and 2011 in various regions of the country in the means of three techniques: individual interviews, discussion groups, and documentations with the main stakeholders of the plan Sesame. This qualitative choice is justified by the numerous and complex interactions which exist between all the elements of the Senegalese system of social welfare and their influence on the living conditions of the elderly. The studied population included a number of 43 people among whom 5 responsible for the plan Sesame, the Ministry of Health, three members of the National Unit of Support for the Financing of the Health and 11 doctors heads of health center. Except these conversations, were organized three discussion groups including all in all 24 people over 60 years chosen among the patients of the only geriatric hospital of Dakar.

The second investigation was a transverse study [8] which took place in the center of Gerontology and Geriatrics of Ouakam from February 21st to 21 Mars 2011. It had for objective to estimate the direct cost of the medicinal care supported by the elderly who benefit of the exemption of healthcare payment policy for the eldery in Senegal. The population of the study was 203 people over 60 years old coming in consultation at the Gerontology and geriatrics of Ouakam. The variables that were examinated are the sociodemographic data, the clinical data, the therapeutic attitude (cost of the biological and radiological examinations and the prescribed prescriptions) and the mode of supply in medicine (purchase to the private pharmacy or in the pharmacy of the hospital). The team also participated in a national study held in 2008 on the living conditions of the elderly in Senegal [3].

\section{Results}

\subsection{Prevalence of the Chronic Diseases}

The elderly are particularly affected by chronic diseases according to the health care inquiries $[3,8]$ the affections most frequently met in consultation in the center of Geriatrics are the arterial High blood pressure (54\%), the diabetes $(16 \%)$, the degenerative osteoarthritis $(18 \%)$, the hypertrophy of the prostate $(10 \%)$ and the cataract $(2 \%)$. The elderly who come in the center of Geriatrics are often people with multiple illnesses; they also suffer from contagious diseases as the malaria or the chronic obstructive pulmonary disease. In Dakar and in Ziguinchor, the elderly evoke the diseases linked to the malnutrition [8].

\subsection{Two Major Stakes for the Elderly People: The Availability and the Accessibility of the Drugs}

Elderly benefit generally from a free access of the care (consultations, help in the diagnosis and essentials medicine). On the other hand medicine intended for the treatment of the chronic pathologies (arterial High blood pressure, diabetes) is not available in the pharmacies of the health care structures so obliging the elderly or their families to buy them in the private pharmacies. However medicine "of specialties" constitutes the main part of the prescription. In the center of Geriatrics, the prescriptions for the elders essentially consist of medicine of specialty, not appearing on the list of essential medicine which are free.

Furthermore, even if the molecule appears on the list of essential medicine, frequent breaks are indicated. As an example, was noted in 2012 that the Captopril molecule intended for the treatment of the arterial high blood pressure were out of stock during 4 months in 2012; it's the same for the molecule Amlopidine which is currently out of stock. However essential medicine, is about those essential and identified for certain categories of the population.

The monthly cost of the medicinal coverage for an old patient was estimated on average between 35.000 and 50.000 $\mathrm{f}$ cfa (50 to 80 euro, 1 euro $=650 \mathrm{~F}$ cfa) while the Guaranteed Minimum Wage is $35.000 \mathrm{f} \mathrm{cfa}$ a month. It means that the cost of the medicinal coverage for the elderly often exceeds the Guaranteed Minimum Wage in Senegal.

Thus, according to a member of the National Federation of the Elderly and Retired Senegal, the Sesame Plan must provide free specialty drugs instead of aspirin and paracetamol that older people themselves can afford. " Another patient says " we are given an order of 25,000 CFA francs to $30.000 \mathrm{f}$ cfa francs (Euro 40/45), while your pension does not exceed $30.000 \mathrm{f}$ cfa (45 euro)." According to a doctor at a health center in Dakar, "drugs that treat the elderly often are not available in health facilities. This is called geriatric medicine. They are mostly not in the list of essential drugs. We made a plea for the National Pharmacy and integrates supply in essential drugs. And we hope they will be available." Besides state of patients in the 3rd age twe would have liked given back us medicine instead of an order because we do not have the means to honor"; "My pension is used to meet the food needs of the family and not buy medicine, I prefer to initially feed my family and my health is after! "; "We are asked to pay the most expensive orders, it means you support larger loads, we must review the plan considered useful and beneficial for all seniors and their families, this plan if we reframed would be of great support and support ." For most of the elderly, to benefit from consultations without medicine is worst than not to receive it because the consultations allow the elderly to discover their pathologies while they do not have the means to take them in charge.

However certain elderly are satisfied with the plan Sesame which take charge of the diseases as those affecting the 
prostate whose intervention cost $250000 \mathrm{f}$ cfa (385 euro) to the elderly before the Plan Sesame. It's the same for other surgical affections (cataract, hernia, fracture of the femoral neck which are from now free. A senior hospital says "If not for the Plan Sesame I have not undergone prostate surgery since its cost is out of financial reach of my meager pension, more kids are unemployed despite their diplomas".

Besides molecules for the treatment of chronic diseases (hypertension, diabetes, osteoarthritis,..) are available in the list of essential drugs. In addition, older people can also benefit from free national program services such as kidney dialysis, tuberculosis......

\subsection{Inappropriate Prescriptions According to the Elderly Related to the Important Recourse of Service}

The small number of geriatricians in Senegal, the absence of training in geriatrics of the prescriber (nurses, doctors, specialists of organs) and the lack of coordination of the prescriptions due to the multiple pathologies $(50 \%$ of the patients have at least two diseases according to the survey) are often responsible of the arisen of unwanted effects for the patient. Indeed, some elderly patients in the survey said "prescribed drugs made me sick and I even felt better after having stopped"; "I really vomit after taking this molecule that does not suit me at all and yet I paid dear"; "The doctor prescribed too many drugs and I do not know if I should take them all at one time and how. "In fact, the importance of the requirements is linked to the heavy reliance of the elderly to health facilities. Indeed, with free elderly patients visit regularly for symptoms even "harmless". According to a health worker, "the number of older consultants increased strongly with the lifting of financial barriers and now they come to the center for nothing. "Indeed, to discourage older people to come all the time in the hospital, some doctors give them go away.

\subsection{An Intense Recourse to the Informal Market of the Drugs}

Because of the high costs of the prescriptions, low financial resources of the elderly and the crisis of the solidarity which affects families, elderly and their families particularly turn to the medicine of the informal market in urban areas where only medicine which appear is the most cheapest. This situation is according to the doctors responsible of the arisen of complications returning more difficult and more expensive the care and the appeal to the traditional medicine. In reality it is rather the families which turn to the market of the informal medicine because many elderly are taken care by their families but they are more and more affected by the effects of the economic crisis. They do not hesitate to assert to the doctors that they turn to the informal market of the medicine. "Doctor, medicine which you prescribe to my father I buy them from the black market where they cost much cheaper compared with the price of pharmacies and moreover they are the same". According to an elderly person "the cost of the prescriptions encourages people to buy obsolete medicine of the black-market or with the doubtful origins" while knowing that it is not good. A doctor specifies that three main causes of the Chronic Renal insufficiency at the elderly are essentially "the arterial high blood pressure, the diabetes, and the effects caused by traditional medicine or of the street". Indeed, the elderly are often aware of the risks of medicine of the informal market. Nevertheless, they are cheaper and their placebo effect have sometimes positive effects on the psychological health of the patients "I take this medicine (it is about an antibiotic) against my joint pains which I buy with the peddler, It is not expensive and it is fine for me; furthermore It is retail sold according to your purchasing power and in the case where you do not have money you can make credit".

\section{Discussion}

\subsection{Prevalence of the Chronic Diseases for the Elderly}

Concerning the clinical data, our study revealed that $52 \%$ of the patients suffered Arterial high blood pressure (29\% of men and $71 \%$ of women). Researches on the morbidmortality of old persons reveal that more and more old persons die as their homologues of the rich countries due to the same pathology. However, in these developed countries they have generally sufficient incomes which allow them to be important consumers of care [9]. This presence of the non transmissible diseases like the diabetes, cancer, the cardiovascular diseases (High Blood Pressure especially) and the mental illness touch the elderly population more and more and influences morbidity and mortality. This is in phase with the preexistent studies: Manga [10] had brought back in a study carried out in a male elderly population in 2004 in Dakar a frequency of High Blood Pressure of $45.62 \%$. Timera [11] brought back a frequency of High Blood Pressure of $79 \%$ in 2004 in a service of cardiology and on a elderly population. For the diabetes, the study brought back to a frequency of $16 \%$ (including $22 \%$ Men and $78 \%$ women). Timera and Manga found similar frequencies in their hospital studies (15\% and 12.5\%). The High Blood Pressure and the diabetes, beside other chronic pathologies (Osteoarthritis (16\%), Prostrate (10\%), Asthma (3\%) and hypercholesterolemia $(3 \%) \ldots$ remain very widespread diseases in the elderly people with a higher incidence among women than at the men. The not covered health problems of the elderly people are also attested in other countries in West Africa as in Burkina Faso [4]. With generally chronic diseases, the elderly people need drugs intended for the covery of these affections.

\subsection{Free Access Without Access to Medicine: a Return at the Time of Before the Initiative of Bamako (IB) and with the Weakness of the State}

The availability of the medicine in the health centers is regarded as one of the major successes of the Initiative of Bamako (IB) [12, 13] whereas within the free access to health care plan, the care remains free but the drugs known as 
of "speciality" are paying. This situation of (free access but unavailable) looks like in many regards to the one instituted after colonization in most African countries [14, 15] and which led to an impasse which led to the initiative of Bamako. It also consisted in supplying free of charge consultations to the people without necessary medicine to pursue the care. Indeed the plan Sesame comes to join a national sanitary context marked by the principles of the Initiative of Bamako. Indeed one of the three pillars of the Initiative of Bamako is the provision of essential drugs to facilitate the access to the care for the whole of the population $[13,16,17]$ but also the recovery of the cost for its perenniality. However, it supposes the participation of the inhabitants in the committees of health in the effort of care. The process of installation of Sesame reveals also other realities of the State in Africa like the presidentialization, the bypass of the technicians to the profit of the politicians, the implementation before the end of the procedures of institutionalization and situational analysis, the electoralization [7].

\subsection{Iatrogenic Diseases Risks}

The multiple pathology of the elderly person is source of poly-medication. Thus the numerous prescriptions for the elderly people as in other contexts $[18,19]$ are factors of morbimortality and involve an increase of the recourse to the ambulatory care, leading to hospitalizations, lengthening the duration of stay of in-patients and thus increase the therapeutic failures, and so increase the therapeutic failures, the pharmaceutical expenses and more probably the iatrogenic healthcare costs. The households buy medicine from $59 \%$ in health professional trainings public and $25 \%$ in private pharmacies [13]. The elderly people who are not able to buy their drugs will be obliged to turn to traditional medicine or the drugs of the "street" which are cheaper or they simply drop the therapy.

\subsection{Medicine for Elderly Person Hardly "Essentialisables”}

The access to medicine is considered since the plan for essential medicine adopted by the resolution W. H. A. 35.27. Of 1982 of the assembly of the WHO as a principle of equity [20]. However, the inequalities between potential recipients of the free health plan (the rural ones and the urban ones) and within the recipients (retired or not) affect the initial objective of social justice whose the Plan had been fixed. Nevertheless the vocation of this plan is identical to the Hospital reform of February 12th 1998 consisting in promoting less expensive generic drugs costing from 30 to $50 \%$. However most of the medicine for the diseases of the elderly are not produced in generic because the elderly are not a priority of the public policies in Africa [4]. On the other hand, in these countries, public authorities turn to the promotion of the policies susceptible to reduce the costs of the care of the more and more elderly [21]. Because of the universal absence of a social security system, 50 to $90 \%$ of the price of medicine in Africa is directly paid by the users while in the developed countries, the existence of a social security cover makes support only 5 to $10 \%$ of the costs of medicine to the users $[22,23]$. The national and international context is not favorable to the registration of the specialized medicine for the elderly people in the list of the essential drugs. At the national level, the registration of new drugs on the list of the essential drugs requires administrative formalities, an invitation to tender, the passage by the agency of Regulation of Procurement contracts... A that is added the hospital reform of 1998 which encourages the health systems to reach financial balance. This new standard compromises the financial accessibility of hospitals and the recourse to the care for the poorest populations. At the same time it affects the finances of the hospitals and their capacity to renew their stock of medicine. At the international level, the elderly people are not a priority public within the plan of Millennium Development Goals $[12,14]$ which gives the priority to new born, children and the women in particular pregnant women. Most of the medicine for the elderly unregistered on the list of essential medicine are still submitted to the ADPIC agreements [24]. Unlike the AIDS, the pathologies which affect the elderly do not benefit generally either from generic medicines or from actors lobbying as those of the AIDS who allowed the price price-cutting of medicine and even their free access [25]. Associations of elderly people are not recognized enough and their political resources are very limited. Moreover, the elderly people in Africa profit very little the support from the international community [26]. Within the States, they do not have the priority. The introduction of this plan then constitutes an exception which makes difficult its implementation because the costs of these drugs remain high and that the elderly people as in the countries of North consume more and more drugs [27, 28].

\subsection{Problems of the Plan Sesame: A General Tendency of the Politics of Exemption of the Payments of Health Care}

Except the peculiarity of these beneficiaries, the problems of implementation of the plan Sesame is also found in other policies of free access in Africa [29, 30]. As in Mali, in Burkina Faso and in Niger [15], the policy of exemption of payments is now transplanted in the official policy of covering of the costs with two parallel systems: a free access of the consultation for Elderly and a payment in point of services for the other patients. Concerning medicine, most of the policies of free access concerned by the disruption of supply of free medicine or delays in repayments of the health care trainings. It is the case in Mali, Niger and Burkina Faso where shortages prevent the distribution of medicine $[15,30]$. The drugs stake questions the recourse to Plan Sesame by the recipients and attests dubious borders of the policies of exemption from payment. The overlap between exemptions and covering of the costs does not facilitate the access to the drugs announced at the origin of the free medical care for the elderly people. So, if the main objective of the policies of exemption of payments in the point of service was intended to raise the financial barrier for the access to healthcare, the 
analysis of the policy of free access for the Elderly demonstrated the necessity of a global approach of the coverage which limits itself not only to the access to the doctors but to the effectiveness of the sanitary coverage to know the accessibility to the care and the availability of medicine.

\subsection{Do the Policies of Free Access Favor the Informal Market of the Medicine?}

While making the consultations free (and not the drugs) and by supporting the recourse to the care of people in situation of precariousness, the policy of exemption from payment like Sesame contribute to feed the informal market of the drug which can divide by two or by three the price of the medicine compared to a formal one. Especially in a context where the elderly people are particularly affected by the effects of the economic crisis [31]. Moreover certain old patients or their children affirm to get drugs in the informal sector since they cost less expensive. As well in Senegal as in Cameroon; it is this economic crisis which is used as alibi to the consumers to resort to this market of the drug in spite of its risks $[32,33]$. This recourse to the drugs of the street can involve much iatrogenic pathology [18] within the population but also in the elderly people. In Senegal, these pathologies are not very known. The informal market of medicine is developed particularly in big cities and especially in Dakar $[34,35]$. This marginal sector, in the beginning is now known and tolerated by public authorities as a parallel sector of marketing of pharmaceutical products today. While the sale of this medicine is punished by the code of public health, we ignore if this tolerance is connected to its politico-religious dimension, because of its connection with the marabouts or because of the communal taxes whose they are the subject.

Beyond the Plan Sesame we can wonder about the risks that the informal market of the drug can involve on the project of Universal health coverage in Senegal when one knows the origins of this drugs and their potential effects about public health. This illicit sale of medicine allows nevertheless to face the underemployment of the people stemming from the drift from the land and so constitutes a social answer for the categories confronted with the difficulties of access to medicine by the official ways [34]. Moreover, most of the customers of this informal market are the people (most of the time the elderly) affected by chronic diseases, who cannot always move to buy [36] themselves their own medicine.

\section{Conclusion}

The not free access to the drugs known as of specialties' compromises the effectiveness of the Sesame Plan and it can reduce its recourse by the recipients. If the exemption from payment of the drugs is a condition for the effectiveness of the Sesame Plan, the current trend does not go in this direction. The project of care systeme of which one of the objectives is to avoid the pitfalls that knew the plan must as a preliminary take into account this non-availability of the drug and the fight against the evaluation of the capacity of the elderly people to buy the drugs necessary is accompanied by a psychosocial shutter rather than of the medical regulations. The institutionalization of the Plan Sesame in Senegal should facilitate the setting on public diary the Health of the elderly at the sub-regional and regional level with the aim of an international lobbying. This could facilitate the registration of medicine for the elderly on the list of essential medicine and to encourage the local or sub-regional production of generic medicines.

\section{References}

[1] National Agency of the Statistics and Demography (2002) general census of the population and the habitat, Dakar.

[2] Ka O (2002) Planning of the athermanous chronic diseases), Mémoire ISED Dakar.

[3] Institut IDEA International (2008): study on the living conditions of the over-sixties years old person in Senegal, Rapport, Dakar.

[4] Berthé Abdramane et Al (2013) Elderly people in sub-Saharan Africa: a vulnerable population, toof ten neglected in the public policies, Public health: 25; 367-71.

[5] Ministry of Health and prevention, Direction of Health, Office of the Health of the Elderly people (2008): Project of implementation of the system of solidarity "Sésame" in favour of the 60 year old elderly people and more in Senegal, Dakar.

[6] Berthé A, Berthé-Sanou L, Konaté B, Hien H, Tou F, Somda $\mathrm{S}$, et al. (2013) Uncovered needs of the elderly people in functional incapacities in Bobo-Dioulasso (Burkina Faso). Rev Epidemol Public Health, 61 (6): 531-37.

[7] Mbaye EM, Ridde V, Ka O (2013) Good intentions are not enough: analysis of a health policy for the elderly people in Senegal: Public Health: 25 (1): 107-12.

[8] Touré M (2012): Assessment of the cost of the care of the elderly person in the center of gerontology and geriatrics of Ouakam, Doctorate Thesis / Dakar n ${ }^{\circ} 21$.

[9] Moynihan R (2006): Inventions of diseases in order to sell drugs, le Monde Diplomatique, 626.

[10] Manga JS (2004) Approach on the sexuality and the erectile dysfunction of the retired subject) $n^{\circ} 60$, Dakar.

[11] Timera D (2004): Epidemiologic, clinical and therapeutic aspects of the High blood pressure, Medicine Thesis, Dakar $\mathrm{n}^{\circ} 45$.

[12] Kereouedan D (2011) International health. Challenges of health in the South, Presses de Sciences Po "Hors-collection", Paris.

[13] Ministry of Health, Direction of Pharmacy and the laboratories national pharmaceutical Policy (2006), Dakar.

[14] Muller P (2003): Public Policies, What do we know?

[15] Olivier de Sardan J-P, et Ridde V (2012): The exemption of payment of the care in Burkina Faso, Mali and Niger: Contradictions of the public policies, Contemporary Africa; 3 (243): 11-32. 
[16] Bayart JF: the State in Africa (1989) the belly policy, Fayard, Paris.

[17] Eboko F (2005) Public Policy and AIDS in Africa: Notebook of African Studies: 178: 2-27.

[18] Ferchichi S, Antoine V (2005) The good use of the drugs by the elderly person: Rev Med Interne 25: 582-90.

[19] Helfter C (2007) Pathologies of senescence: social information; 2 (138): 117-18.

[20] WHO, Ministry of the Health of Senegal: Evaluation of the pharmaceutical sector in Senegal: Report of investigation 2003. http://apps.who.int/medicinedocs/documents/s16430f/s16430f.p df

[21] Bernier Nf. Mallon I (2009) Is getting older a problem?, Lien so et po, RIAC; 62: $180 \mathrm{p}$.

[22] Mc Coy, D, Hall JA, Ridge M A (2012) Systematic review of the literature for Evidence on Health Facility committies in Low and Middle-Income Countries, Health Policy Planning; 27 (6): 449-66.

[23] Velasquez, G (1999): essential drugs and globalization, conference of the AIDE "Pharmaceutical Brevets, innovations and public health" Toulouse; 28-30 January.

[24] Léveque F, Ménière Y (2003) Economy of the intellectual property: La Découverte, Repères, Paris.

[25] Castro DR, le Gall J-M, Jablonski O (2009) Improving Health of the HIV positive people with the VIH: SERONET, a new tool of the community approach, Public health: 21: 129-39.

[26] Ridde V, Blanchet K: Debates and challenges around free care in Africa " back to the future "? Cahiers of studies and research Free, 2009; 19 (2): 101-6.
[27] Henrard JC (2002) The French system of assistance and care for the elderly: Health, society, solidarity: 2: 72-81.

[28] Ndiaye O, Dieme EJG (2007): Evaluation of the initiatives of subsidies and social fund, Rapport d'évaluation, Dakar.

[29] Ridde V, Queille L, Kafando Y (2009): Capitalizations of public policies of exemption of the payment of the care in Africa: "return towards the future"? Cahiers of studies and research Free; 19 (2): 101-6.

[30] Seck A, Lazure G, Diane M (2012): Experiments of ageing lived by Senegalese women of 60 years old and more, alive in the community. Qualitative Research; 31 (1): 1 - 23.

[31] Ouattara A (2009) Purchase of drugs of the informal market in Africa: Comprehension of an "irrational" behavior), Market Management; 9 (1): 59-73.

[32] Pinel J (2005) Generic, counterfeit, quality: Which drugs for the countries in the process of development? Les tribunes de la Santé; 1 (6): 49 - 55.

[33] Fassin D (1985) From illegal work to the unofficial, The networks of illicit sale of medicine in Senegal: Notebook of African Studies: 25 (98): 161-77.

[34] Velasquez G (1999): Essential Drugs and Globalization Symposium HELP " Pharmaceutical Patents, innovation and public health," Toulouse.

[35] Gurwitz JH, Field TS, Harrold LR, et al (2003) Incidence and preventability of adverse drug events among older persons in the ambulatory setting: JAMA 289: 1107-16.

[36] Van L, W, Brouwere V (2000): Health status and health of the State in Sub-Saharan Africa), Contemporary Africa; 195: 175190. 